Article

\title{
Comparative Studies of Interactions between Fluorodihydroquinazolin Derivatives and Human Serum Albumin with Fluorescence Spectroscopy
}

\author{
Yi Wang ${ }^{1,2}$, Meiqing Zhu ${ }^{1}$, Feng Liu ${ }^{2}$, Xiangwei Wu ${ }^{1}$, Dandan Pan ${ }^{1}$, Jia Liu ${ }^{1,3}$, Shisuo Fan ${ }^{1}$, \\ Zhen Wang ${ }^{1}$, Jun Tang ${ }^{1}$, Risong $\mathrm{Na}^{1,3}$, Qing X. $\mathrm{Li}^{4}$, Rimao Hua ${ }^{1, *}$ and Shangzhong Liu ${ }^{2, *}$ \\ 1 Department of Science of Pesticides, School of Resources and Environment, Anhui Agricultural University, \\ No. 130 Changjiang West Road, Hefei 230036, China; wangyi@ahau.edu.cn (Y.W.); \\ zhumeiqing@ahau.edu.cn (M.Z.); wxw@ahau.edu.cn (X.W.); dandanpan@ahau.edu.cn (D.P.); \\ ljia198346@163.com (J.L.); fanshisuo@ahau.edu.cn (S.F.); zwang@ahau.edu.cn (Z.W.); \\ tangjun@ahau.edu.cn (J.T.); risongna@163.com (R.N.) \\ 2 Department of Applied Chemistry, China Agricultural University, No. 2 Yuanmingyuan West Road, \\ Beijing 100193, China; caulf0527@163.com \\ 3 Collaborative Innovation Center of Henan Grain Crops, National Key Laboratory of Wheat and Maize Crop \\ Science, College of Plant Protection, Henan Agricultural University, Wenhua Road No. 95, \\ Zhengzhou 450002, China \\ 4 Department of Molecular Biosciences and Bioengineering, University of Hawaii, 1955 East-West Road, \\ Honolulu, HI 96822, USA; qingl@hawaii.edu \\ * Correspondence: rimaohua@ahau.edu.cn (R.H.); shangzho@cau.edu.cn (S.L.); \\ Tel./Fax: +86-551-6578-6320 (R.H.); +86-10-6273-1010 (S.L.)
}

Academic Editor: Bela Torok

Received: 9 September 2016; Accepted: 12 October 2016; Published: 14 October 2016

\begin{abstract}
In the present study, 3-(fluorobenzylideneamino)-6-chloro-1-(3,3-dimethylbutanoyl)-phenyl2,3-dihydroquinazolin-4(1H)-one (FDQL) derivatives have been designed and synthesized to study the interaction between fluorine substituted dihydroquinazoline derivatives with human serum albumin (HSA) using fluorescence, circular dichroism and Fourier transform infrared spectroscopy. The results indicated that the FDQL could bind to HSA, induce conformation and the secondary structure changes of HSA, and quench the intrinsic fluorescence of HSA through a static quenching mechanism. The thermodynamic parameters, $\Delta H, \Delta S$, and $\Delta G$, calculated at different temperatures, revealed that the binding was through spontaneous and hydrophobic forces and thus played major roles in the association. Based on the number of binding sites, it was considered that one molecule of FDQL could bind to a single site of HSA. Site marker competition experiments indicated that the reactive site of HSA to FDQL mainly located in site II (subdomain IIIA). The substitution by fluorine in the benzene ring could increase the interactions between FDQL and HSA to some extent in the proper temperature range through hydrophobic effect, and the substitution at meta-position enhanced the affinity greater than that at para- and ortho-positions.
\end{abstract}

Keywords: synthesis; fluorine; fluorescence quenching; human serum albumin; FDQL

\section{Introduction}

Human serum albumin (HSA) is the most abundant plasma protein in the circulatory system of the human body and contains 585 amino acids. HSA plays a key function in physiological and pharmacological processes. For example, HSA can transport several endogenous and exogenous compounds, like fatty acids, nutrients, steroids, certain metal ions, hormones and drugs, and also significantly affect their biological activity in pharmacology through altering their pharmacokinetic 
properties [1-7]. Binding of drugs to plasma proteins may strongly influence their distribution and elimination [8], for instance, many drug candidates were rendered ineffective due to their unusually high binding affinity to HSA [9-14]. Therefore, investigation of the binding interaction between drugs and HSA is of importance in pharmacology and pharmacodynamics.

Heterocyclic structures play a pivotal role in many pharmaceutical, agrochemical, and veterinary products, like quinazolines. An increasing number of quinazoline derivatives have been reported to possess antibacterial [15], anticancer [16], antitubercular [17], anti-HIV [18], antifungal [19], analgesic [20], anti-inflammatory [21], anticonvulsant [22], antiparkinson [23], anthelmintic [24], anti-histaminic [25], and antihypertensive activities [26]. Much attention has been focused on their structures and bioactivity. Little information is, however, available on the interactions of quinazolines with HSA. Fluorine substituents have often been introduced in developing pharmaceutical products and agrochemicals to improve the biological activity and metabolism. However, it is hard to estimate whether the compounds are effective with introducing a fluorine substituent by molecule designing. Especially because there is no information about the impact of fluorine substituent position on the interactions between quinazoline derivatives and HSA.

We have previously reported the impact of halogen substituents on the interactions between quinazoline derivatives and HSA [27]. In the present study, new 6-chloro-1-(3,3-dimethylbutanoyl)3-(fluorobenzylideneamino)-phenyl-2,3-dihydroquinazolin-4(1H)-one (FDQL) derivatives (3b-d) (Scheme 1) were designed and synthesized, and their binding interactions to HSA at three temperatures were investigated via fluorescence spectroscopy. The obtained information about the molecular interactions, including quenching mechanism, binding mode, binding sites, binding constants, thermodynamic parameters, and conformation of HSA may offer a better understanding of its biological action in vivo. The influence of the position of fluorine substituent on FDQL-HSA interactions was studied under simulated physiological conditions using 3-(benzylideneamino)6-chloro-1-(3,3-dimethyl-butanoyl)-2-phenyl-2,3-dihydroquinazolin-4(1H)-one as a reference compound. The results provide a quantitative understanding of fluorine substitution effects on FDQL-HSA interactions to some extent, which could be useful for further design of potential biologically active quinazolinone derivatives.

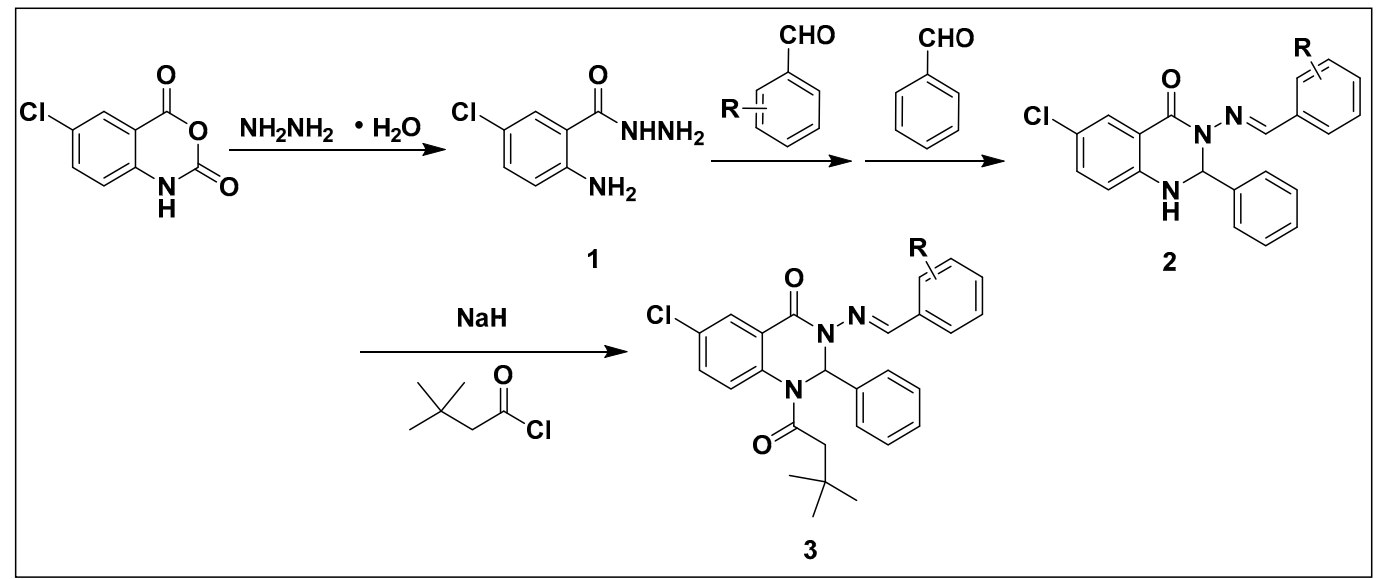

Scheme 1. Synthetic route of 6-Chloro-3-fluorobenzylideneamino-2-phenyl-2,3-dihydroquinazolin$4(1 H)$-one (FDQL). $\mathrm{R}=\mathrm{H}(\mathbf{3 a}), p-\mathrm{F}(\mathbf{3 b}), m-\mathrm{F}(\mathbf{3 c}), o-\mathrm{F}$ (3d). $p$, para; $m$, meta; $o$, ortho; and $\mathrm{F}$, fluorine.

\section{Results and Discussion}

\subsection{Synthesis}

In the previous work, the introduction of $t$-butylacetyl moieties on quinazolines improved their binding to HSA to some extent through hydrophobic action [27]. Thus, based on 3a that was previously 
reported, we designed and synthesized compounds $\mathbf{3 b}-\mathbf{d}$ to study the impact of fluorine substituents on the interactions of HSA and quinazolines. These new compounds have been characterized with NMR and HRMS spectra (see Supplementary Materials).

\subsection{Fluorescence Quenching Mechanism}

The effect of FDQL on the fluorescence emission spectra of HSA was first tested with a fluorescence spectrophotometer, and obtained data were plotted in Figure 1. This figure clearly displays that the fluorescence intensity of HSA consistently decreased in the presence of increasing concentration of FDQL due to fluorescence quenching by FDQL, and a complex formation between FDQL and HSA.
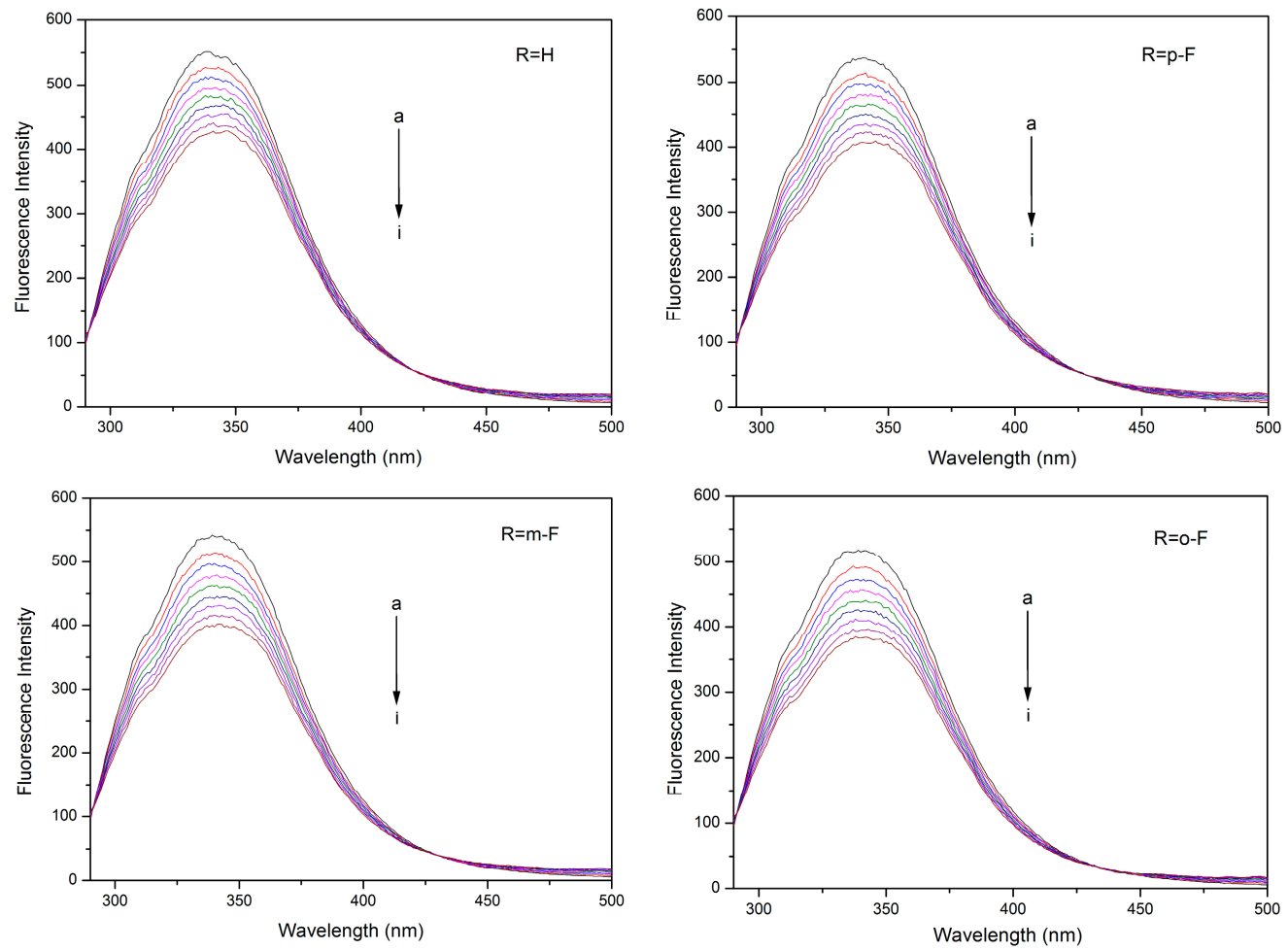

Figure 1. Fluorescence quenching spectra of HSA at different concentrations of FDQL at $298 \mathrm{~K}$; $\lambda_{\mathrm{ex}}=280 \mathrm{~nm} ; \mathrm{C}(\mathrm{HSA})=1.0 \times 10^{-6} \mathrm{M} ; \mathrm{C}(\mathrm{FDQL}) /\left(\times 10^{-6} \mathrm{M}\right),(\mathrm{a}-\mathrm{i}) 0.000,1.333,2.667,4.000,5.333,6.667$, $8.000,9.333$, and 10.667 respectively.

In general, the fluorescence of HSA could be dynamically or statically quenched by an organic compound. As to which one works herein, some variable tests about temperature, viscosity, and lifetime measure were employed and the Stern-Volmer Equation (1) [28] were used to analyze the data for determining the mechanism of quenching fluorescence of HSA by FDQL.

$$
F_{0} / F=1+K_{\mathrm{SV}}[\mathrm{Q}]=1+K q \tau_{0}[\mathrm{Q}]
$$

where $F_{0}$ and $F$ are the fluorescence intensities of HSA without and with the quencher, respectively, $K_{\mathrm{SV}}$ is the linear Stern-Volmer quenching constant, $\mathrm{Kq}$ is the bimolecular quenching constant, [Q] is the concentration of the quencher, $\tau_{0}$ is the average lifetime of the biomolecule in the absence of the quencher $\left(\tau_{0}=10^{-8} \mathrm{~s}^{-1}\right)$ [29]. The Stern-Volmer plot curves were linear with high values, and the calculated $K_{\mathrm{SV}}$ and $\mathrm{Kq}$ at the corresponding temperatures were listed in Table 1.

It is known that linear Stern-Volmer plots indicate one type of quenching mechanism as predominant, either static or dynamic [30]. Moreover, in Table 1, the values of $\mathrm{Kq}$ at different temperatures were much higher than the limiting diffusion rate constant of biomolecules $\left(k_{\mathrm{d}} \approx 2.0 \times 10^{10} \mathrm{M}^{-1} \cdot \mathrm{s}^{-1}\right)$ [31-34], which revealed static quenching via forming a complex. 
Table 1. Stern-Volmer quenching constants for interactions of FDQL with HSA at different temperatures.

\begin{tabular}{|c|c|c|c|c|c|}
\hline Compound & $\mathrm{T}(\mathrm{K})$ & $K_{\mathrm{SV}}\left(\times 10^{4} \mathrm{M}^{-1}\right)$ & $K q\left(\times 10^{12} M^{-1} \cdot s^{-1}\right)$ & $R^{\mathrm{a}}$ & $S D^{\mathrm{b}}$ \\
\hline \multirow{3}{*}{$\mathrm{R}=\mathrm{H}$} & 298 & 2.77 & 2.77 & 0.99916 & 0.00605 \\
\hline & 307 & 2.98 & 2.98 & 0.99898 & 0.00677 \\
\hline & 316 & 3.23 & 3.23 & 0.99919 & 0.00513 \\
\hline \multirow{3}{*}{$\mathrm{R}=p-\mathrm{F}$} & 298 & 3.11 & 3.11 & 0.99931 & 0.00451 \\
\hline & 307 & 3.25 & 3.25 & 0.99933 & 0.00466 \\
\hline & 316 & 3.52 & 3.52 & 0.99946 & 0.00453 \\
\hline \multirow{3}{*}{$\mathrm{R}=m-\mathrm{F}$} & 298 & 3.24 & 3.24 & 0.99941 & 0.00436 \\
\hline & 307 & 3.44 & 3.44 & 0.99889 & 0.00633 \\
\hline & 316 & 3.63 & 3.63 & 0.99924 & 0.00553 \\
\hline \multirow{3}{*}{$\mathrm{R}=o-\mathrm{F}$} & 298 & 3.30 & 3.30 & 0.99973 & 0.00299 \\
\hline & 307 & 3.36 & 3.36 & 0.99942 & 0.00449 \\
\hline & 316 & 3.40 & 3.40 & 0.99907 & 0.00573 \\
\hline
\end{tabular}

${ }^{\mathrm{a}} \mathrm{R}$ is the correlation coefficient. ${ }^{\mathrm{b}} S D$ is the standard deviation for the $K_{\mathrm{SV}}$ values.

For a complex formation process, the affinity constant $K_{\mathrm{a}}$ of the binding between FDQL and HSA was analyzed by modified Stern-Volmer Equation (2) [35-37]:

$$
F_{0} /\left(F_{0}-F\right)=f_{\mathrm{a}}{ }^{-1} \cdot K_{\mathrm{a}}{ }^{-1} \cdot[\mathrm{Q}]^{-1}+f_{\mathrm{a}}{ }^{-1}
$$

where $f_{\mathrm{a}}$ represents the fraction of accessible fluorescence and $K_{\mathrm{a}}$ is the effective quenching constant. $F_{0} /\left(F_{0}-F\right)$ is linear with the reciprocal value of the quencher concentration [Q], and the slope equals to the value of $f_{\mathrm{a}}{ }^{-1} \cdot K_{\mathrm{a}}{ }^{-1}$. According to the modified Stern-Volmer Equation, data were calculated to obtain the linear plots at different temperatures shown in Figure 2. The corresponding values of $K_{a}$ in Table 2 showed that the affinity constants all increased after substitution by fluorine atom on the benzene ring.
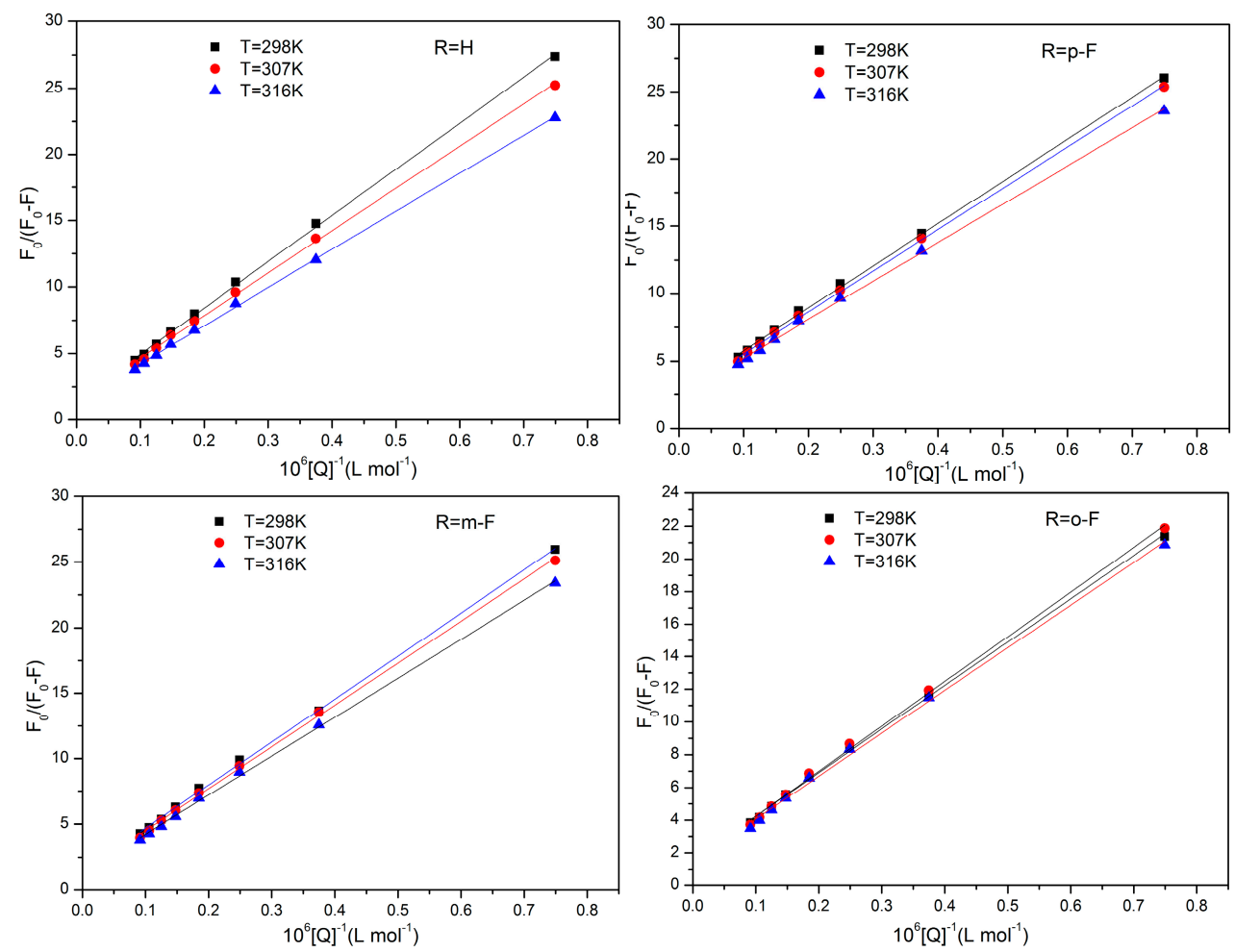

Figure 2. Modified Stern-Volmer plots of FDQL-HSA systems. 
Table 2. Thermodynamic parameters of FDQL-HSA binding systems at different temperatures.

\begin{tabular}{|c|c|c|c|c|c|c|}
\hline Compound & $\mathbf{T}(\mathbf{K})$ & $K_{\mathrm{a}}\left(\times 10^{4} \mathrm{M}^{-1}\right)$ & $R^{\mathrm{a}}$ & $\Delta H\left(\mathrm{~kJ} \cdot \mathrm{mol}^{-1}\right)$ & $\Delta G\left(\mathrm{~kJ} \cdot \mathrm{mol}^{-1}\right)$ & $\Delta S\left(\mathrm{~J} \cdot \mathrm{mol}^{-1} \cdot \mathrm{K}^{-1}\right)$ \\
\hline \multirow{3}{*}{$\mathrm{R}=\mathrm{H}$} & 298 & 2.16 & 0.99949 & \multirow{3}{*}{7.14} & -24.72 & \multirow{3}{*}{106.92} \\
\hline & 307 & 2.34 & 0.99969 & & -25.68 & \\
\hline & 316 & 2.54 & 0.99963 & & -26.65 & \\
\hline \multirow{3}{*}{$\mathrm{R}=p-\mathrm{F}$} & 298 & 2.33 & 0.99945 & \multirow{3}{*}{8.83} & -24.92 & \multirow{3}{*}{113.24} \\
\hline & 307 & 2.59 & 0.99967 & & -25.93 & \\
\hline & 316 & 2.85 & 0.99967 & & -26.95 & \\
\hline \multirow{3}{*}{$\mathrm{R}=m-\mathrm{F}$} & 298 & 2.73 & 0.99979 & \multirow{3}{*}{5.49} & -25.31 & \multirow{3}{*}{103.36} \\
\hline & 307 & 2.92 & 0.99960 & & -26.24 & \\
\hline & 316 & 3.10 & 0.99967 & & -27.17 & \\
\hline \multirow{3}{*}{$\mathrm{R}=o-\mathrm{F}$} & 298 & 2.46 & 0.99956 & \multirow{3}{*}{4.50} & -25.04 & \multirow{3}{*}{99.13} \\
\hline & 307 & 2.58 & 0.99949 & & -25.93 & \\
\hline & 316 & 2.72 & 0.99912 & & -26.83 & \\
\hline
\end{tabular}

${ }^{\text {a }} R$ is the correlation coefficient.

\subsection{Binding Sites and Identification of Binding Sites on HSA}

For the static quenching process, the number of binding sites can be obtained on the double-logarithmic equation [38-40]

$$
\lg \left[\left(F_{0}-F\right) / F\right]=\lg K_{\mathrm{b}}+n \lg [\mathrm{Q}]
$$

where $F_{0}$ and $F$ are the fluorescence intensities without and with the ligand, and $K_{\mathrm{b}}$ and $\mathrm{n}$ are the binding constant and the number of binding sites, respectively. According to Equation (3), the number of binding sites $n$ can be determined on the slope of a straight line produced by the plots of $\lg \left[\left(F_{0}-F\right) / F\right]$ versus $\log [Q]$. The data shown in Table 3 demonstrated a good linear relationship and $n$ approximates to 1 , indicating that only one site in HSA is reactive to FDQL.

Table 3. Binding numbers of FDQL to HSA.

\begin{tabular}{ccccc}
\hline Compound & $\mathbf{T}(\mathbf{K})$ & $\boldsymbol{n}$ & $\boldsymbol{R}^{\mathbf{a}}$ & $\boldsymbol{S D}^{\mathbf{b}}$ \\
\hline \multirow{3}{*}{$\mathrm{R}=\mathrm{H}$} & 298 & 0.99314 & 0.99945 & 0.01088 \\
& 307 & 0.98423 & 0.99947 & 0.01059 \\
& 316 & 0.97492 & 0.99928 & 0.01220 \\
\hline \multirow{2}{*}{$\mathrm{R}=p-\mathrm{F}$} & 298 & 0.97047 & 0.99914 & 0.01329 \\
& 307 & 0.98121 & 0.99942 & 0.01100 \\
& 316 & 0.98160 & 0.99947 & 0.01054 \\
\hline & 298 & 0.98976 & 0.99949 & 0.01043 \\
$\mathrm{R}=m-\mathrm{F}$ & 307 & 1.00621 & 0.99926 & 0.01276 \\
& 316 & 0.99960 & 0.99942 & 0.01126 \\
\hline \multirow{3}{*}{$\mathrm{R}=o-\mathrm{F}$} & 298 & 0.94907 & 0.99959 & 0.00895 \\
& 307 & 0.97208 & 0.99936 & 0.01150 \\
& 316 & 0.98093 & 0.99884 & 0.01562 \\
\hline
\end{tabular}

${ }^{\mathrm{a}} R$ is the correlation coefficient. ${ }^{\mathrm{b}} S D$ is the standard deviation for the $n$ values.

HSA is a globular protein composed of three homologous $\alpha$-helical domains (I-III), and each domain contains two subdomains (A and B). The principal regions of ligand binding sites on HSA locate in hydrophobic cavities in subdomains IIA and IIIA [41]. Sjöholm et al. [42] reported that phenylbutazone (PB), flufenamic acid (FA), and digitoxin (Dig) bind subdomain IIA (site I), subdomain IIIA (site II), and site III, respectively, which were used in the present study as the site markers in competitive experiments to identify the binding sites of FDQL on HSA. The fluorescence quenching data in the presence of site markers were analyzed with the modified Stern-Volmer Equation, and 
the values of binding constants listed in Table 4 showed a remarkable decrease after the addition of FA, but relatively small changes after the addition of PB and Dig. Therefore, FDQL would be mainly bound to HSA in site II (subdomain IIIA).

Table 4. Effects of the site probe on the binding constants of FDQL to HSA.

\begin{tabular}{ccccc}
\hline Compound & Site Marker & $\boldsymbol{K}_{\mathbf{a}}\left(\times \mathbf{1 0}^{\mathbf{4}} \mathbf{M}^{\mathbf{- 1}}\right)$ & $\boldsymbol{R}^{\mathbf{a}}$ & $\boldsymbol{S D}^{\mathbf{b}}$ \\
\hline \multirow{3}{*}{$\mathrm{R}=\mathrm{H}$} & Blank & 2.16 & 0.99949 & 0.26651 \\
& PB & 1.88 & 0.99962 & 0.27020 \\
& FA & 1.04 & 0.99948 & 0.25962 \\
& Dig & 2.18 & 0.99938 & 0.24163 \\
$\mathrm{R}=p-\mathrm{F}$ & Blank & 2.33 & 0.99945 & 0.23559 \\
& PB & 2.44 & 0.99960 & 0.23309 \\
& FA & 2.10 & 0.99976 & 0.22148 \\
$\mathrm{D}=m-\mathrm{F}$ & Dig & 2.43 & 0.99954 & 0.20943 \\
& Blank & 2.73 & 0.99979 & 0.14653 \\
& PB & 2.08 & 0.99931 & 0.26689 \\
& FA & 1.65 & 0.99969 & 0.26159 \\
& Dig & 2.78 & 0.99955 & 0.18883 \\
\hline & Blank & 2.46 & 0.99956 & 0.18871 \\
$\mathrm{R}=o-\mathrm{F}$ & PB & 2.25 & 0.99922 & 0.25466 \\
& FA & 1.72 & 0.99972 & 0.22793 \\
& Dig & 2.54 & 0.99914 & 0.24946 \\
\hline
\end{tabular}

${ }^{\mathrm{a}} \mathrm{R}$ is the correlation coefficient. ${ }^{\mathrm{b}} S D$ is the standard deviation for the $K_{\mathrm{a}}$ values.

\subsection{Thermodynamic Parameters and Binding Modes}

The interaction forces between ligands and biomolecules include probably electrostatic interactions, multiple hydrogen bonds, van der Waals force, hydrophobic and steric contacts, and so on [43]. Generally, the signs and magnitudes of the thermodynamic parameters enthalpy change $(\Delta H)$ and entropy change $(\Delta S)$ can account for the main forces involved in the binding process.

If $\Delta H$ does not vary significantly in the temperature range studied, both $\Delta H$ and $\Delta S$ can be evaluated from the Van't Hoff equation:

$$
\ln K_{\mathrm{a}}=-\Delta H / R T+\Delta S / \mathrm{R}
$$

where $K_{\mathrm{a}}$ is analogous to the associative binding constants at the corresponding temperature and $\mathrm{R}$ is the gas constant.

To elucidate the interaction between FDQL and HSA, the thermodynamic parameters were calculated from the Van't Hoff plots (Figure 3). $\Delta H$ was calculated from the slope of the Van't Hoff relationship. The free energy change $(\Delta G)$ was then estimated from the following equation:

$$
\Delta G=\Delta H-T \Delta S
$$

The negative signs for free energy $(\Delta G)$ of the FDQL-HSA systems indicated that the interaction processes were spontaneous (Table 2). The signs for $\Delta H$ and $\Delta S$ of the binding reaction were both found to be positive, which indicated that the binding was mainly entropy-derived and the enthalpy was unfavorable for it, according Ross and Subramanian [44]. Thus, the hydrophobic forces played a major role in the binding process of FDQL to HSA.

With use of 3-(benzylideneamino)-6-chloro-1-(3,3-dimethylbutanoyl)-2-phenyl-2,3-dihydro quinazolin-4(1H)-one as a reference compound, the changes of $\Delta H$ and $\Delta S$ ( $\Delta \Delta H$ and $\Delta \Delta S$, respectively) were compared and studied after incorporating different fluorine substituent positions in the benzene ring. The signs of $\Delta \Delta H$ and $\Delta \Delta S$ listed in Table 5 showed that the binding affinity was enhanced by hydrophobic interaction after incorporating para-fluoro atoms, but by van der Waals force after 
incorporating meta-fluoro and ortho-fluoro atoms upon on the thermodynamic law summarized by Ross and Subramanian.

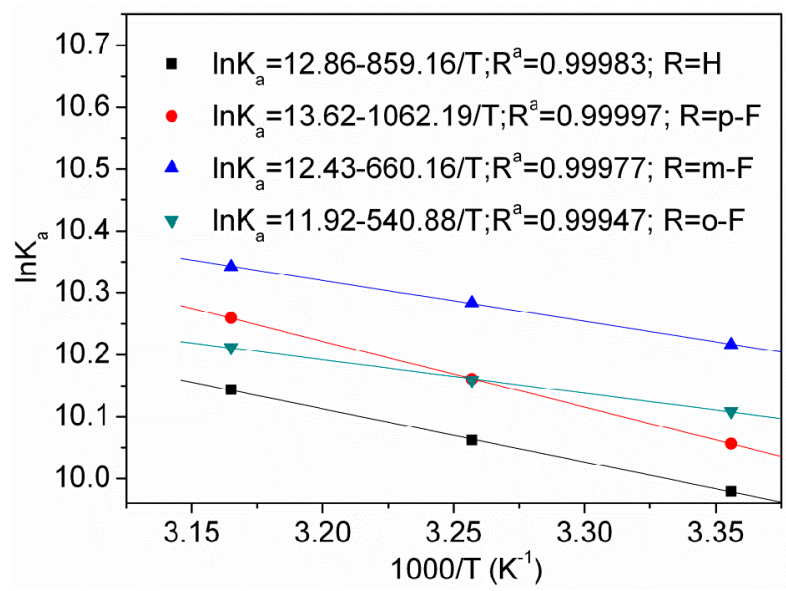

Figure 3. Van't Hoff plots for FDQL-HSA systems.

Table 5. The values of $\Delta \Delta H$ and $\Delta \Delta S$ in FDQL-HSA systems.

\begin{tabular}{ccc}
\hline Compound & $\boldsymbol{\Delta} \boldsymbol{\Delta} \boldsymbol{H}\left(\mathbf{k J} \cdot \mathbf{~ m o l}^{-\mathbf{1}}\right)$ & $\boldsymbol{\Delta} \boldsymbol{\Delta S}\left(\mathbf{J} \cdot \mathbf{~ m o l}^{-\mathbf{1}} \cdot \mathbf{K}^{-\mathbf{1}}\right)$ \\
\hline $\mathrm{R}=p-\mathrm{F}$ & 1.69 & 6.32 \\
$\mathrm{R}=m-\mathrm{F}$ & -1.65 & -3.56 \\
$\mathrm{R}=o-\mathrm{F}$ & -2.64 & -7.79 \\
\hline
\end{tabular}

In addition, the data at the corresponding temperature in Table 6 displayed the $\Delta G$ changes $(\Delta \Delta G)$ of interactions of FDQL-HSA after incorporating fluorine atom on the benzene ring. The values showed that the $\Delta \Delta G$ changed only slightly as the temperature changed, and the negative sign of $\Delta \Delta G$ indicated that incorporation of substitution fluorine atom increased the binding affinity in the FDQL-HSA systems. Furthermore, it was found that the meta-fluoro substitution enhanced the affinity more greatly than that of para-fluoro and ortho-fluoro substitution.

Table 6. Values of $\Delta \Delta G$ at corresponding temperature in FDQL-HSA systems.

\begin{tabular}{lcccc}
\hline & $\mathbf{T}(\mathbf{K})$ & $\mathbf{R}=\boldsymbol{p}-\mathbf{F}$ & $\mathbf{R}=\boldsymbol{m}-\mathbf{F}$ & $\mathbf{R}=\boldsymbol{o}-\mathbf{F}$ \\
\hline & 298 & -0.20 & -0.59 & -0.32 \\
$\Delta \mathbf{\Delta} G\left(\mathbf{k J} \cdot \mathbf{m o l}^{-\mathbf{1}}\right)$ & 307 & -0.25 & -0.56 & -0.25 \\
& 316 & -0.30 & -0.52 & -0.18 \\
\hline
\end{tabular}

\subsection{HSA Conformational Change by CD and FT-IR Measurements}

Currently, CD spectroscopy is a sensitive technique to provide some information about the secondary structure of proteins. In order to explore any molecular conformation changes of HSA occurring in the binding process, the Far-UV CD measurements for HSA in the absence and presence of FDQL were carried out in the range of 200-260 nm. The CD spectra of HSA and FDQL-HSA complex were shown in Figure 4 which exhibited two negative bands in the UV region at $208 \mathrm{~nm}$ and $222 \mathrm{~nm}$, showing characteristic of $\alpha$-helix structure units of protein [45]. The intensities of the negative bands increased with the addition of FDQL without a change in the position and shape of peak. The calculated results of the fractions of $\alpha$-Helix, $\beta$-sheet, $\beta$-Turn, and Random Coil structures were listed in Table 7. These results indicated that the structure of HSA after addition of FDQLs is still predominantly $\alpha$-helix. Overall, FDQL-HSA complex forms in the solution and the binding process can induce some secondary structure change of HSA. 


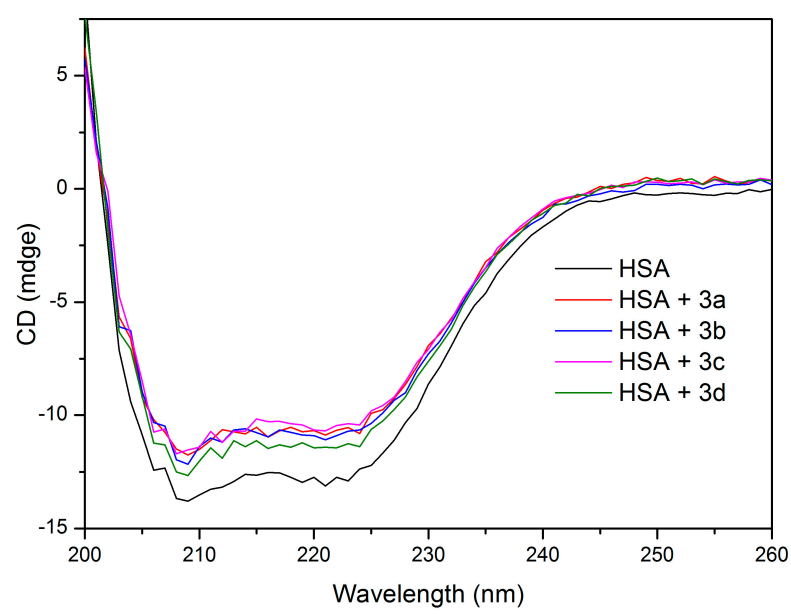

Figure 4. Far-UV CD spectra of the FDQL-HSA system: $\mathrm{C}_{\mathrm{HSA}}=1 \mu \mathrm{M}$ and $1 \mu \mathrm{M}$ HSA $+2 \mu \mathrm{M}$ FDQL.

Table 7. Conformation changes of the secondary structure of HSA with and without FDQL.

\begin{tabular}{ccccc}
\hline \multirow{2}{*}{ Sample } & \multicolumn{4}{c}{ Secondary Structure (\%) } \\
\cline { 2 - 5 } & $\boldsymbol{\alpha}$-Helix & $\beta$-Sheet & $\beta$-Turn & Random Coil \\
\hline HSA & 38.8 & 23.6 & 11.0 & 26.6 \\
HSA + 3a (1:2) & 35.8 & 22.7 & 14.2 & 27.2 \\
HSA + 3b (1:2) & 36.8 & 17.6 & 17.0 & 28.6 \\
HSA + 3c (1:2) & 35.1 & 16.3 & 19.7 & 28.9 \\
HSA + 3d (1:2) & 38.0 & 23.9 & 12.5 & 25.5 \\
\hline
\end{tabular}

FT-IR spectroscopy was performed to confirm the CD results, and structural changes of HSA after binding with FDQL were observed with FT-IR (Figure 5). According to the literature [46], the FT-IR spectra for HSA monitored over a range of $1700-1500 \mathrm{~cm}^{-1}$ reveal the presence of two bands, the amide I band (1700-1600 $\mathrm{cm}^{-1}$, mainly $\mathrm{C}=\mathrm{O}$ stretch) and the amide II band (1600-1500 $\mathrm{cm}^{-1}$, a C-N stretch coupled with N-H bending mode), which are related to the secondary structure of the protein. After addition of FDQLs to HSA, the peak position of amide I was shifted from $1652 \mathrm{~cm}^{-1}$ to $1621 \mathrm{~cm}^{-1}$, and amide II was moved from $1541 \mathrm{~cm}^{-1}$ to $1513 \mathrm{~cm}^{-1}$. In addition, the intensity of the amide I and amide II band decreased and the peak shape changed, indicating that FDQLs interacted with the $\mathrm{C}=\mathrm{O}$ and $\mathrm{C}-\mathrm{N}$ groups in the protein structural subunits. These observations jointly support that FDQLs could induce conformational changes in HSA during the binding process, which agreed with the results of CD experiments.

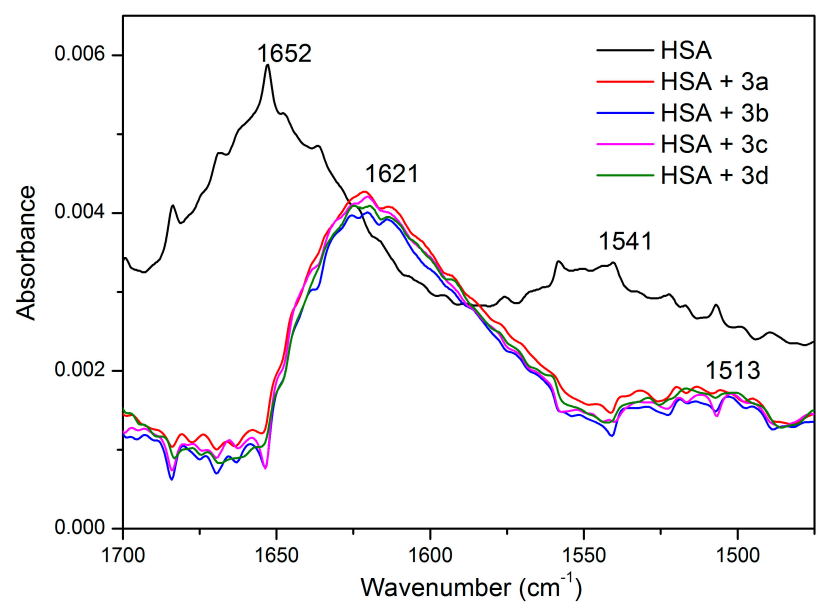

Figure 5. FTIR spectra of free HSA $(10 \mu \mathrm{M})$ and the FDQL-HSA complex $([\mathrm{FDQL}]=20 \mu \mathrm{M})$. 


\section{Experimental Section}

\subsection{General Methods and Materials}

Melting points were measured with a Fisher-Johns melting point apparatus (Cole-Parmer Co., Shanghai, China) without correction. Nuclear magnetic resonance (NMR) spectra were recorded with a $400-\mathrm{MHz}$ spectrometer (Bruker, Billerica, MA, USA) and 600-MHz spectrometer (Agilent Technologies, Inc., Santa Clara, CA, USA) using tetramethylsilane (TMS) as an internal standard. IR spectra were recorded on a Bruker Tensor 27 (Bruker Optics GmbH, Ettlingen, Germany) in $\mathrm{KBr}$ pellets in the range $4000-400 \mathrm{~cm}^{-1}$. Mass spectra were recorded using an HPLC-1100/TOF MS high resolution mass spectrometer (Agilent Technologies). All fluorescence spectra were measured on a Cary Eclipse fluorescence spectrophotometer (Agilent Technologies) equipped with a thermostat bath. Quartz cuvettes with a 1-cm path length and 3-mL volume were used for all measurements. All $\mathrm{pH}$ measurements were completed with a PHS-25 digital $\mathrm{pH}$ meter (Shanghai REX Instrument Factory, Shanghai, China). HSA ( $\geq 99.9$, fatty-acid free), purchased from Sigma-Aldrich (St. Louis, MO, USA), was used without further purification. PB, FA, and Dig were of analytical grade, and purchased from the National Institute for Control of Pharmaceutical and Bioproducts (Beijing, China), and the stock solutions were prepared in absolute ethanol. All other commercial reagents were used as obtained from Sigma-Aldrich, Alfa Aesar (Ward Hill, MA, USA), and J\&K (Beijing, China). Flash column chromatography with silica gel was used to purify the crude products.

\subsection{Fluorescence Titration Experiments}

All HSA solutions were prepared in buffer solution ( $0.1 \mathrm{M}$ Tris base and $0.1 \mathrm{M} \mathrm{NaCl}$ at $\mathrm{pH} 7.4)$, and the HSA stock solutions were kept in the dark at $4{ }^{\circ} \mathrm{C}$. The solution $(3.0 \mathrm{~mL})$ containing $1.0 \times 10^{-6} \mathrm{M}$ HSA was titrated by successive additions of $8.0 \times 10^{-4} \mathrm{M}$ ethanol stock solution of FDQL (the final concentration is $1.333-10.667 \times 10^{-6} \mathrm{M}$ ). Titrations were done manually by using trace syringes, and the fluorescence intensity was measured (excitation at $280 \mathrm{~nm}$ and emission at $337 \mathrm{~nm}$ ). All experiments were conducted at three temperatures $(298,307$, and $316 \mathrm{~K})$.

\subsection{Site Marker Competitive Experiments}

Binding location studies between FDQL and HSA in the presence of three site makers (phenylbutazone, flufenamic acid, digitoxin) were measured according to the fluorescence titration methods. The concentration of HSA and site makers were all stabilized at $1.0 \times 10^{-6} \mathrm{M}$. The solution of FDQL was then gradually added to the phenylbutazone-HSA, flufenamic acid-HSA, or digitoxin-HSA mixtures, and the fluorescence intensity was recorded $\left(\lambda_{\mathrm{ex}} 280 \mathrm{~nm}\right.$ and $\left.\lambda_{\mathrm{em}} 337 \mathrm{~nm}\right)$.

\subsection{Circular Dichroism Spectra Studies}

The CD measurements were performed on a Jasco-810 spectropolarimeter (Jasco, Japan) at $298 \mathrm{~K}$ with a thermostatically controlled cell holder attached to a NeslabRTE-110 water bath with an accuracy of $\pm 0.1{ }^{\circ} \mathrm{C}$. The instrument was sufficiently purged with $99.9 \%$ dry nitrogen gas and calibrated with D-10-camphorsulfonicacid before starting the apparatus. Each spectrum was performed with the use of a quartz cuvette of $0.1 \mathrm{~cm}$ path length and taken at wavelengths between 200 and $260 \mathrm{~nm}$ with $1 \mathrm{~nm}$ step resolution and the average of five successive scans recorded at a speed of $50 \mathrm{~nm} \cdot \mathrm{min}^{-1}$ and response time of $1 \mathrm{~s}$. All observed $C D$ spectra were baselines subtracted for buffer and the secondary structure was computed using the Jasco standard spectra analysis software package.

\subsection{Fourier Transform Infrared (FT-IR) Measurements}

FT-IR measurements were carried out at room temperature on a Thermo Scientific Nicolet iS50 FTIR spectrometer (Thermo, Tewksbury, MA, USA) equipped with a germanium attenuated total reflection (ATR) accessory. All spectra were taken via 32 scans with a resolution of $4 \mathrm{~cm}^{-1}$. 
The FT-IR spectra of HSA in the absence and presence of FDQL were first collected in the range of $500 \mathrm{~cm}^{-1}-4000 \mathrm{~cm}^{-1}$ and the absorbance of the buffer solution (Tris- $\mathrm{HCl}$ buffer solution at $\mathrm{pH} 7.40$ ) was then subtracted.

\subsection{Synthesis of (un)Substituted Phenyl-2,3-dihydroquinazolin-4(1H)-one Derivatives FDQL 3a-d}

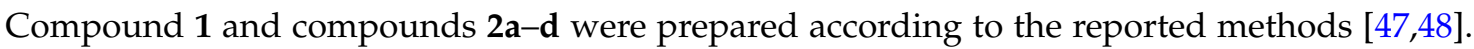
Their properties were as follows:

2-Amino-5-chlorobenzohydrazide (1): white crystals, yield 85\%; m.p. $139.6-140.5{ }^{\circ} \mathrm{C} ;{ }^{1} \mathrm{H}-\mathrm{NMR}(400 \mathrm{MHz}$, DMSO-d $\left.d_{6}\right) \delta 9.60(\mathrm{~s}, 1 \mathrm{H}), 7.48(\mathrm{~d}, J=2.5 \mathrm{~Hz}, 1 \mathrm{H}), 7.16(\mathrm{dd}, J=8.8,2.5 \mathrm{~Hz}, 1 \mathrm{H}), 6.74(\mathrm{~d}, J=8.8 \mathrm{~Hz}, 1 \mathrm{H})$, $6.46(\mathrm{~s}, 2 \mathrm{H}), 4.42(\mathrm{~s}, 2 \mathrm{H})$.

3-(Benzylideneamino)-6-chloro-2-phenyl-2,3-dihydroquinazolin-4(1H)-one (2a): light yellow solid, yield 75.3\%; m.p. 193.5-194.5 ${ }^{\circ} \mathrm{C} ;{ }^{1} \mathrm{H}-\mathrm{NMR}(400 \mathrm{MHz}$, Chloroform-d) $\delta 9.16(\mathrm{~s}, 1 \mathrm{H}), 7.86(\mathrm{~d}, J=2.4 \mathrm{~Hz}, 1 \mathrm{H})$, 7.61-7.52 (m, 2H), 7.40-7.34 (m, 2H), 7.33-7.22 (m, 6H), 7.21-7.17 (m, 1H), $6.58(\mathrm{~d}, J=8.6 \mathrm{~Hz}, 1 \mathrm{H}), 6.21$ $(\mathrm{s}, 1 \mathrm{H}), 4.82(\mathrm{~s}, 1 \mathrm{H})$.

6-Chloro-3-(2-fluorobenzylideneamino)-2-phenyl-2,3-dihydroquinazolin-4(1H)-one (2b): light yellow crystal, yield 63.7\%; m.p. 193.3-194.1 ${ }^{\circ} \mathrm{C} ;{ }^{1} \mathrm{H}-\mathrm{NMR}(400 \mathrm{MHz}$, Chloroform- $d) \delta 9.25(\mathrm{~d}, J=1.2 \mathrm{~Hz}, 1 \mathrm{H}), 7.85(\mathrm{~d}$, $J=2.5 \mathrm{~Hz}, 1 \mathrm{H}), 7.39-7.32(\mathrm{~m}, 2 \mathrm{H}), 7.29(\mathrm{~d}, J=2.1 \mathrm{~Hz}, 1 \mathrm{H}), 7.28-7.23(\mathrm{~m}, 5 \mathrm{H}), 7.19(\mathrm{~d}, J=1.8 \mathrm{~Hz}, 1 \mathrm{H})$, $7.02-6.96(\mathrm{~m}, 1 \mathrm{H}), 6.59(\mathrm{~d}, J=8.6 \mathrm{~Hz}, 1 \mathrm{H}), 6.20(\mathrm{~s}, 1 \mathrm{H}), 4.82(\mathrm{~s}, 1 \mathrm{H})$.

6-Chloro-3-(3-fluorobenzylideneamino)-2-phenyl-2,3-dihydroquinazolin-4(1H)-one (2c): light yellow crystal, yield 60.5\%; m.p. 204.3-206.1 ${ }^{\circ} \mathrm{C} ;{ }^{1} \mathrm{H}-\mathrm{NMR}(400 \mathrm{MHz}$, Chloroform-d) $\delta 9.13(\mathrm{~s}, 1 \mathrm{H}), 7.91-7.80(\mathrm{~m}, 1 \mathrm{H})$, 7.61-7.49 (m, 2H), 7.42-7.30 (m, 2H), 7.31-7.23 (m, 3H), 7.21-7.16 (m, 1H), 7.00-6.92 (m, 2H), 6.64-6.53 $(\mathrm{m}, 1 \mathrm{H}), 6.23-6.15(\mathrm{~m}, 1 \mathrm{H}), 4.88-4.77(\mathrm{~m}, 1 \mathrm{H})$.

6-Chloro-3-(4-fluorobenzylideneamino)-2-phenyl-2,3-dihydroquinazolin-4(1H)-one (2d): white crystal, yield 65.3\%; m.p. 200.1-202.0 ${ }^{\circ} \mathrm{C}$; ${ }^{1} \mathrm{H}-\mathrm{NMR}(400 \mathrm{MHz}$, Chloroform-d) $\delta 9.32$ (s, 1H), 7.90-7.85 (m, 1H), 7.73 $(\mathrm{td}, J=7.5,1.8 \mathrm{~Hz}, 1 \mathrm{H}), 7.38-7.31(\mathrm{~m}, 2 \mathrm{H}), 7.28-7.24(\mathrm{~m}, 4 \mathrm{H}), 7.20-7.16(\mathrm{~m}, 2 \mathrm{H}), 7.05-6.95(\mathrm{~m}, 2 \mathrm{H}), 6.58$ $(\mathrm{d}, J=8.6 \mathrm{~Hz}, 1 \mathrm{H}), 6.23(\mathrm{~d}, J=1.9 \mathrm{~Hz}, 1 \mathrm{H}), 4.86(\mathrm{~s}, 1 \mathrm{H})$.

For the preparation of compounds $3 \mathbf{a}-\mathbf{d}$, the corresponding compound $\mathbf{2}(3 \mathrm{mmol})$ in anhydrous tetrahydrofuran $(30 \mathrm{~mL})$ was cooled to $0{ }^{\circ} \mathrm{C}$ with an ice bath, and sodium hydride $(3.6 \mathrm{mmol})$ was added. The mixture was stirred for $0.5 \mathrm{~h}$ at $0{ }^{\circ} \mathrm{C}$ followed by another $1.0 \mathrm{~h}$ at room temperature. tert-Butylacetyl chloride $(3.6 \mathrm{mmol})$ in anhydrous tetrahydrofuran $(5 \mathrm{~mL})$ was added slowly at $0{ }^{\circ} \mathrm{C}$ in $0.5 \mathrm{~h}$, and then the mixture was stirred again at room temperature overnight. The solvent was removed under vacuum, and the residue was then purified by flash chromatography using hexane and ethyl acetate $(v / v=6: 1)$ as the eluent to obtain the title compounds.

3-(Benzylideneamino)-6-chloro-1-(3,3-dimethylbutanoyl)-2-phenyl-2,3-dihydroquinazolin-4(1H)-one (3a): white solid, yield 49.5\%; m.p. $149.5-150.8{ }^{\circ} \mathrm{C} ;{ }^{1} \mathrm{H}-\mathrm{NMR}\left(600 \mathrm{MHz}, \mathrm{DMSO}-d_{6}\right) \delta 9.17(\mathrm{~s}, 1 \mathrm{H}), 7.81(\mathrm{~m}$, $4 \mathrm{H}), 7.61(\mathrm{~s}, 2 \mathrm{H}), 7.52-7.41(\mathrm{~m}, 3 \mathrm{H}), 7.33-7.13(\mathrm{~m}, 5 \mathrm{H}), 2.67$ (s, 2H), $0.95(\mathrm{~s}, 9 \mathrm{H}) ;{ }^{13} \mathrm{C}-\mathrm{NMR}(151 \mathrm{MHz}$, DMSO- $\left.d_{6}\right) \delta 171.56,158.59,152.50,136.82,136.54,134.42,133.39,131.45,130.95,129.34,129.27,129.02$, $128.16,128.01,127.57,126.33,125.90,44.73,32.14,29.86$; HRMS: $m / z$ calc for $\mathrm{C}_{27} \mathrm{H}_{26} \mathrm{ClN}_{3} \mathrm{O}_{2}[\mathrm{M}+\mathrm{H}]^{+}$ 460.1786 , found 460.1776

6-Chloro-1-(3,3-dimethylbutanoyl)-3-(2-fluorobenzylideneamino)-2-phenyl-2,3-dihydroquinazolin-4(1H)-one (3b): white solid, yield 53.3\%; m.p. $172.2-173.0{ }^{\circ} \mathrm{C} ;{ }^{1} \mathrm{H}-\mathrm{NMR}\left(600 \mathrm{MHz}, \mathrm{DMSO}-d_{6}\right) \delta 9.17(\mathrm{~s}, 1 \mathrm{H})$, 7.96-7.66 (m, 4H), $7.61(\mathrm{~s}, 2 \mathrm{H}), 7.52-7.38(\mathrm{~m}, 1 \mathrm{H}), 7.37-7.11(\mathrm{~m}, 6 \mathrm{H}), 2.79-2.57(\mathrm{~m}, 2 \mathrm{H}), 0.95(\mathrm{~s}, 9 \mathrm{H})$; ${ }^{13}$ C-NMR (151 MHz, DMSO- $\left.d_{6}\right) \delta 171.56,158.55,136.83,130.50,130.44,129.36,129.28,129.03,128.17$, 126.33, 125.85, 116.55, 116.40, 44.72, 39.76, 32.14, 29.86; IR $\left(\mathrm{v} \cdot \mathrm{cm}^{-1}\right)$ : 3677.1, 2958.4, 1891.5, 1670.9, $1603.8,1511.2,1371.9,1315.9,1233.3,1164.6,839.6,768.9,755.1,700.0,594.9,540.1$; HRMS: $m / z$ calc for $\mathrm{C}_{27} \mathrm{H}_{25} \mathrm{ClFN}_{3} \mathrm{O}_{2}[\mathrm{M}+\mathrm{H}]^{+} 478.1692$, found 478.1680 . 
6-Chloro-1-(3,3-dimethylbutanoyl)-3-(3-fluorobenzylideneamino)-2-phenyl-2,3-dihydroquinazolin-4(1H)-one (3c): white solid, yield 50.9\%; m.p. 114.2-116.0 ${ }^{\circ} \mathrm{C} ;{ }^{1} \mathrm{H}-\mathrm{NMR}\left(600 \mathrm{MHz}, \mathrm{DMSO}-d_{6}\right) \delta 9.20(\mathrm{~s}, 1 \mathrm{H}), 7.81$ (s, 2H), 7.71-7.55 (m, 4H), 7.54-7.44 (m, 1H), 7.38-7.10 (m, 6H), 2.67 (m, 2H), $0.95(\mathrm{~s}, 9 \mathrm{H}) ;{ }^{13} \mathrm{C}-\mathrm{NMR}(151$ MHz, DMSO- $\left.d_{6}\right) \delta 171.56,158.69,150.38,137.05,136.87,133.51,131.46,131.41,129.32,129.28,129.04$, $128.15,128.05,127.61,126.31,125.77,124.54,118.20,118.06,114.09,113.94,47.77,44.73,32.13,29.85 ;$ IR $\left(\mathrm{v} \cdot \mathrm{cm}^{-1}\right): 3430.0,2957.5,1693.5,1668.1,1479.5,1421.4,1359.6,1278.3,1232.0,1146.0,755.9,704.9,542.2 ;$ HRMS: $m / z$ calc for $\mathrm{C}_{27} \mathrm{H}_{25} \mathrm{ClFN}_{3} \mathrm{O}_{2}[\mathrm{M}+\mathrm{H}]^{+} 478.1692$, found 478.1677.

6-Chloro-1-(3,3-dimethylbutanoyl)-3-(4-fluorobenzylideneamino)-2-phenyl-2,3-dihydroquinazolin-4(1H)-one (3d): white solid, yield 56.3\%; m.p. 148.0-149.1 ${ }^{\circ} \mathrm{C}$; ${ }^{1} \mathrm{H}-\mathrm{NMR}\left(600 \mathrm{MHz}, \mathrm{DMSO}-d_{6}\right) \delta 9.56(\mathrm{~s}, 1 \mathrm{H})$, 7.99-7.86 (m, 1H), 7.84-7.66 (m, 2H), $7.62(\mathrm{~s}, 2 \mathrm{H}), 7.54(\mathrm{~m}, 1 \mathrm{H}), 7.47(\mathrm{~m}, 1 \mathrm{H}), 7.34-7.15(\mathrm{~m}, 6 \mathrm{H}), 2.67$ (s, 2H), 0.96 (s, 9H); ${ }^{13} \mathrm{C}-\mathrm{NMR}\left(151 \mathrm{MHz}, \mathrm{DMSO}-d_{6}\right) \delta 171.57,162.43,160.76,159.08,158.58,145.92$, $136.78,134.42,133.54,131.46,129.35,129.31,129.27,129.07,128.16,128.02,127.59,127.12,126.33,126.27$, $125.77,125.51,125.49,122.05,116.71,116.57,44.73,32.10,29.86,29.82 ; \mathrm{IR}\left(\mathrm{v} \cdot \mathrm{cm}^{-1}\right): 3423.2,2962.9$, 1670.1, 1481.4, 1431.8, 1359.8, 1125.8, 830.8, 755.8, 596.9; HRMS: $m / z$ calc for $\mathrm{C}_{27} \mathrm{H}_{25} \mathrm{ClFN}_{3} \mathrm{O}_{2}[\mathrm{M}+\mathrm{H}]^{+}$ 478.1692 , found 478.1682 .

\section{Concluding Remarks}

In summary, interactions of four FDQLs with HSA have been studied with fluorescence spectroscopy, CD, and FT-IR experiments. The experimental results indicated that the FDQL could bind to HSA in the site II (subdomain IIIA), induce conformation and the secondary structure changes of HSA and quench the intrinsic fluorescence of HSA through a static quenching mechanism. The quenching of HSA fluorescence takes place with 1:1 complex formation between FDQL and HSA. In the complex formation between HSA and FDQL, hydrophobic forces play a significant role. The studies of the FDQL-HSA interactions showed that substitution of a fluorine atom on the benzene ring could enhance the binding affinity through the steric and hydrophobic effects; specifically, meta-fluoro substitution enhanced the binding affinity most greatly by hydrophobic interaction. This study has provided some valuable information for further research into the rational design of this series of compounds. As the functions of the same substituent in aromatic compounds are relatively consistent and stable, the obtained results about varying fluorine substitution positions are hopefully valuable for guiding molecular design and modification of benzene rings.

Supplementary Materials: Supplementary materials can be accessed at: http:/ /www.mdpi.com/1420-3049/21/ $10 / 1373 /$ s1.

Acknowledgments: This work was performed in part by the National High Technology Research and Development Program of China (2013AA102804B), the National Natural Science Foundation of China (NSFC) (No. 31601657, 31272062, 31572033 and 21602043), the Anhui Agricultural University Youth Fund Project (2014zr003, yj2015-25), the Performance Project of Key laboratory of Anhui Province (1506c085006), the Natural Science Foundation of Anhui Province of China (1408085MKL36), and the Foundation for the Excellent Youth Scholars of Anhui Province (2013SQRL016ZD).

Author Contributions: This research was carried on by all authors. Y. Wang, R. Hua, and S. Liu designed the theme of the study as well as manuscript preparation. M. Zhu, F. Liu, X. Wu, D. Pan, J. Liu, S. Fan, Z. Wang, J. Tang, and R. Na participated in the synthesis of compounds and fluorescence experiments. Q.X. Li contributed to data interpretation and manuscript revision.

Conflicts of Interest: The authors declare no conflict of interest.

\section{References}

1. Kandagal, P.B.; Ashoka, S.; Seetharamappa, J.; Shaikh, S.M.T.; Jadegoud, Y.; Ijare, O.B. Study of the interaction of an anticancer drug with human and bovine serum albumin: Spectroscopic approach. J. Pharm. Biomed. Anal. 2006, 41, 393-399. [CrossRef] [PubMed]

2. Wu, S.; Liu, Y.; Liu, S. Spectroscopic studies on the interaction of human serum albumin and water-soluble carboxyl carbon nanotubes. Spectrosc. Spect. Anal. 2016, 36, 1109-1115. 
3. Ma, X.; Yan, J.; Xu, K.; Guo, L.; Li, H. Binding mechanism of trans-n-caffeoyltyramine and human serum albumin: Investigation by multi-spectroscopy and docking simulation. Bioorg. Chem. 2016, 66, 102-110. [CrossRef] [PubMed]

4. Rohacova, J.; Marin, M.L.; Miranda, M.A. Complexes between fluorescent cholic acid derivatives and human serum albumin. A photophysical approach to investigate the binding behavior. J. Phys. Chem. B 2010, 114, 4710-4716. [CrossRef] [PubMed]

5. Housaindokht, M.R.; Rouhbakhsh Zaeri, Z.; Bahrololoom, M.; Chamani, J.; Bozorgmehr, M.R. Investigation of the behavior of hsa upon binding to amlodipine and propranolol: Spectroscopic and molecular modeling approaches. Spectrochim. Acta A Mol. Biomol. Spectrosc. 2012, 85, 79-84. [CrossRef] [PubMed]

6. Ding, F.; Zhang, L.; Diao, J.; Li, X.; Ma, L.; Sun, Y. Human serum albumin stability and toxicity of anthraquinone dye alizarin complexone: An albumin-dye model. Ecotoxicol. Environ. Saf. 2012, 79, 238-246. [CrossRef] [PubMed]

7. Ding, F.; Peng, W. Biophysical evaluation of protein structural flexibility for ligand biorecognition in solid solution. Phys. Chem. Chem. Phys. 2016, 18, 6595-6606. [CrossRef] [PubMed]

8. Alam, P.; Abdelhameed, A.S.; Rajpoot, R.K.; Khan, R.H. Interplay of multiple interaction forces: Binding of tyrosine kinase inhibitor nintedanib with human serum albumin. J. Photochem. Photobiol. B 2016, 157, 70-76. [CrossRef] [PubMed]

9. Liu, X.; Du, Y. Study on the binding of chiral drug duloxetine hydrochloride to human serum albumin. Eur. J. Med. Chem. 2010, 45, 4043-4049. [CrossRef] [PubMed]

10. Abdollahpour, N.; Asoodeh, A.; Saberi, M.R.; Chamani, J. Separate and simultaneous binding effects of aspirin and amlodipine to human serum albumin based on fluorescence spectroscopic and molecular modeling characterizations: A mechanistic insight for determining usage drugs doses. J. Lumin. 2011, 131, 1885-1899. [CrossRef]

11. Wang, T.; Xiang, B.; Wang, Y.; Chen, C.; Dong, Y.; Fang, H.; Wang, M. Spectroscopic investigation on the binding of bioactive pyridazinone derivative to human serum albumin and molecular modeling. Colloids Surf. B Biointerfaces 2008, 65, 113-119. [CrossRef] [PubMed]

12. Gao, W.; Li, N.; Chen, G.; Xu, Y.; Chen, Y.; Hu, S.; Hu, Z. Binding studies of costunolide and dehydrocostuslactone with hsa by spectroscopy and atomic force microscopy. J. Lumin. 2011, 131, 2063-2071. [CrossRef]

13. Bijari, N.; Shokoohinia, Y.; Ashrafi-Kooshk, M.R.; Ranjbar, S.; Parvaneh, S.; Moieni-Arya, M.; Khodarahmi, R. Spectroscopic study of interaction between osthole and human serum albumin: Identification of possible binding site of the compound. J. Lumin. 2013, 143, 328-336. [CrossRef]

14. Afrin, S.; Riyazuddeen; Rabbani, G.; Khan, R.H. Spectroscopic and calorimetric studies of interaction of methimazole with human serum albumin. J. Lumin. 2014, 151, 219-223. [CrossRef]

15. Mabkhot, Y.N.; Al-Har, M.S.; Barakat, A.; Aldawsari, F.D.; Aldalbahi, A.; Ul-Haq, Z. Synthesis, anti-microbial and molecular docking studies of quinazolin-4(3H)-one derivatives. Molecules 2014, 19, 8725-8739. [CrossRef] [PubMed]

16. Ghorab, M.M.; Alsaid, M.S.; Al-Dosari, M.S.; El-Gazzar, M.G.; Parvez, M.K. Design, synthesis and anticancer evaluation of novel quinazoline-sulfonamide hybrids. Molecules 2016, 21, 189. [CrossRef] [PubMed]

17. Yadav, R.R.; Khan, S.I.; Singh, S.; Khan, I.A.; Vishwakarma, R.A.; Bharate, S.B. Synthesis, antimalarial and antitubercular activities of meridianin derivatives. Eur. J. Med. Chem. 2015, 98, 160-169. [CrossRef] [PubMed]

18. Wang, Z.; Wang, M.; Yao, X.; Li, Y.; Tan, J.; Wang, L.; Qiao, W.; Geng, Y.; Liu, Y.; Wang, Q. Design, synthesis and antiviral activity of novel quinazolinones. Eur. J. Med. Chem. 2012, 53, 275-282. [CrossRef] [PubMed]

19. Farghaly, T.A.R.; Edrees, M.M.; Mosselhi, M.A. Synthesis, tautomeric structure and antimicrobial activity of 3-arylhydrazono-4-phenyl-[1,2,4]-triazepino[2,3-a]quinazoline-2,7(1h)-diones. Molecules 2012, 17, 8483-8493. [CrossRef] [PubMed]

20. Abdel-Aziz, A.A.M.; Abou-Zeid, L.A.; ElTahir, K.E.H.; Mohamed, M.A.; Abu El-Enin, M.A.; El-Azab, A.S. Design, synthesis of 2,3-disubstituted $4(3 H)$-quinazolinone derivatives as anti-inflammatory and analgesic agents: Cox-1/2 inhibitory activities and molecular docking studies. Bioorg. Med. Chem. 2016, 24, 3818-3828. [CrossRef] [PubMed]

21. Abdel-Aziz, A.A.M.; Abou-Zeid, L.A.; El Tahir, K.E.H.; Ayyad, R.R.; El-Sayed, M.A.A.; El-Azab, A.S. Synthesis, anti-inflammatory, analgesic, cox-1/2 inhibitory activities and molecular docking studies of substituted 2-mercapto-4(3H)-quinazolinones. Eur. J. Med. Chem. 2016, 121, 410-421. [CrossRef] [PubMed] 
22. Georgey, H.; Abdel-Gawad, N.; Abbas, S. Synthesis and anticonvulsant activity of some quinazolin-4-(3H)-one derivatives. Molecules 2008, 13, 2557-2569. [CrossRef] [PubMed]

23. Khattab, S.N.; Haiba, N.S.; Asal, A.M.; Bekhit, A.A.; Amer, A.; Abdel-Rahman, H.M.; El-Faham, A. Synthesis and evaluation of quinazoline amino acid derivatives as mono amine oxidase (mao) inhibitors. Bioorg. Med. Chem. 2015, 23, 3574-3585. [CrossRef] [PubMed]

24. Dahiya, R.; Kumar, A.; Yadav, R. Synthesis and biological activity of peptide derivatives of iodoquinazolinones/nitroimidazoles. Molecules 2008, 13, 958-976. [CrossRef] [PubMed]

25. Alagarsamy, V.; Sharma, H.K.; Parthiban, P.; Singh, J.C.H.; Murugan, S.T.; Solomon, V.R. Cheminform abstract: 4-(3-Methoxyphenyl)-1-substituted-4H-[1,2,4]triazolo [4,3-a]quinazolin-5-ones: New class of $h$ 1-antihistaminic agents. Cheminform 2009, 40, 5-9. [CrossRef]

26. Bandurco, V.T.; Wong, E.M.; Levine, S.D.; Hajos, Z.G. Antihypertensive pyrrolo[1,2-c]quinazolines and pyrrolo[1,2-c]quinazolinones. J. Med. Chem. 1981, 24, 1455-1460. [CrossRef] [PubMed]

27. Liu, F.; Wang, Y.; Lv, C.; Wang, L.; Ou, J.; Wang, M.; Liu, S. Impact of halogen substituents on interactions between 2-phenyl-2,3-dihydroqulinazolin-4(1H)-one derivatives and human serum albumin. Molecules 2012, 17, 2000. [CrossRef] [PubMed]

28. Lakowicz, J.R. (Ed.) Mechanisms and dynamics of fluorescence quenching. In Principles of Fluorescence Spectroscopy; Springer: Boston, MA, USA, 2006; pp. 331-351.

29. Lakowicz, J.R.; Weber, G. Quenching of fluorescence by oxygen. Probe for structural fluctuations in macromolecules. Biochemistry 1973, 12, 4161-4170. [CrossRef] [PubMed]

30. Papadopoulou, A.; Green, R.J.; Frazier, R.A. Interaction of flavonoids with bovine serum albumin: A fluorescence quenching study. J. Agric. Food Chem. 2005, 53, 158-163. [CrossRef] [PubMed]

31. Ware, W.R. Oxygen quenching of fluorescence in solution: An experimental study of the diffusion process. J. Phys. Chem. 1962, 66, 316-320. [CrossRef]

32. Chaves, O.A.; Amorim, A.P.O.; Castro, L.H.E.; Sant'Anna, C.M.R.; de Oliveira, M.C.C.; Cesarin-Sobrinho, D.; Netto-Ferreira, J.C.; Ferreira, A.B.B. Fluorescence and docking studies of the interaction between human serum albumin and pheophytin. Molecules 2015, 20, 19526-19539. [CrossRef] [PubMed]

33. Cacita, N.; Nikolaou, S. Studying the interaction between trinuclear ruthenium complexes and human serum albumin by means of fluorescence quenching. J. Lumin. 2016, 169, 115-120. [CrossRef]

34. Cheng, X.; Fan, X.; Jiang, F.; Liu, Y.; Lei, K. Resonance energy transfer, ph-induced folded states and the molecular interaction of human serum albumin and icariin. Luminescence 2015, 30, 1026-1033. [CrossRef] [PubMed]

35. Niu, M.; Hong, M.; Chang, G.; Li, X.; Li, Z. A comparative study of cytotoxicity and interaction with DNA/protein of five transition metal complexes with schiff base ligands. J. Photochem. Photobiol. B 2015, 148, 232-341. [CrossRef] [PubMed]

36. Zhang, W.; Zhang, Q.; Wang, F.; Yuan, L.; Xu, Z.; Jiang, F.; Liu, Y. Comparison of interactions between human serum albumin and silver nanoparticles of different sizes using spectroscopic methods. Luminescence 2015, 30, 397-404. [CrossRef] [PubMed]

37. Cheng, Z.; Liu, R.; Jiang, X.; Xu, Q. The interaction between cepharanthine and two serum albumins: Multiple spectroscopic and chemometric investigations. Luminescence 2014, 29, 504-515. [CrossRef] [PubMed]

38. Trivedi, V.D.; Vorum, H.; Honore, B.; Qasim, M.A. Molecular basis of indomethacin-human serum albumin interaction. J. Pharm. Pharmacol. 1999, 51, 591-600. [CrossRef] [PubMed]

39. Cui, F.; Fan, J.; Li, J.; Hu, Z. Interactions between 1-benzoyl-4-p-chlorophenyl thiosemicarbazide and serum albumin: Investigation by fluorescence spectroscopy. Bioorg. Med. Chem. 2004, 12, 151-157. [CrossRef] [PubMed]

40. Tang, K.; Qin, Y.; Lin, A.; Hu, X.; Zou, G. Interaction of daunomycin antibiotic with human serum albumin: Investigation by resonant mirror biosensor technique, fluorescence spectroscopy and molecular modeling methods. J. Pharm. Biomed. Anal. 2005, 39, 404-410. [CrossRef] [PubMed]

41. Cheng, F.; Wang, Y.; Li, Z.; Dong, C. Fluorescence study on the interaction of human serum albumin with bromsulphalein. Spectrochim. Acta A Mol. Biomol. Spectrosc. 2006, 65, 1144-1147. [CrossRef] [PubMed]

42. Sjöholm, I.; Ekman, B.; Kober, A.; Ljungstedt-Påhlman, I.; Seiving, B.; Sjödin, T. Binding of drugs to human serum albumin: Xi. The specificity of three binding sites as studied with albumin immobilized in microparticles. Mol. Pharmacol. 1979, 16, 767-777. [PubMed] 
43. Leckband, D. Measuring the forces that control protein interactions. Annu. Rev. Biophys. Biomol. Struct. 2003, 29, 1-26. [CrossRef] [PubMed]

44. Ross, P.D.; Subramanian, S. Thermodynamics of protein association reactions: Forces contributing to stability. Biochemistry 1981, 20, 3096-3102. [CrossRef] [PubMed]

45. Kelly, S.M.; Jess, T.J.; Price, N.C. How to study proteins by circular dichroism. Biochim biophys acta. Biochim. Biophys. Acta 2005, 1751, 119-139. [CrossRef] [PubMed]

46. Yue, Y.; Sun, Y.; Dong, Q.; Liu, R.; Yan, X.; Zhang, Y.; Liu, J. Interaction of human serum albumin with novel imidazole derivatives studied by spectroscopy and molecular docking. Luminescence 2016, 31, 671-681. [CrossRef] [PubMed]

47. Sircar, J.C.; Capiris, T.; Kesten, S.J.; Herzig, D.J. Pyrazolo[5,1-b]quinazolin-9-ones: A new series of antiallergic agents. J. Med. Chem. 1981, 24, 735-742. [CrossRef] [PubMed]

48. Fulop, F.; Simeonov, M.; Pihlaja, K. Formation of 1,2-dihydroquinazolin-4(3H)-ones. Reinvestigation of a recently reported 1,3,4-benzotriazepine synthesis. Tetrahedron 1992, 48, 531-538. [CrossRef]

Sample Availability: Samples of the compounds are available from authors.

(C) 2016 by the authors; licensee MDPI, Basel, Switzerland. This article is an open access article distributed under the terms and conditions of the Creative Commons Attribution (CC-BY) license (http://creativecommons.org/licenses/by/4.0/). 